Chatrakul Na Ayudhya, U., Prouska, R. and Lewis, S. (2015), "Work-life balance can benefit business during financial crisis and austerity", Human Resource Management International Digest, Vol. 23, Iss. 5 pp. 25-28.

\title{
Work-life balance can benefit business during financial crisis and austerity
}

\section{Is there a place for work-life balance (WLB) initiatives and practices in times of austerity?}

We believe that WLB initiatives are good for business and a good way of managing recession and austerity. Three studies - one in the UK and two in South Europe - point to the positive impact of WLB initiatives for business during times of financial crisis.

\section{Evidence from the UK}

Suzan Lewis, Professor of organizational psychology at Middlesex University, examined at a conference named "Diversity: a Practitioner's Journey", held at Middlesex University, London, how the recession and austerity have affected the public sector in the UK in terms of their WLB policies and practices. The study is based on interviews with HR Directors and senior managers in a range of organizations (see Lewis et al., 2014).

The study found that the experience of and investment in infrastructure to support work flexibility and WLB proved useful in difficult economic times. During this period there was a shift in HR practice from making WLB policies available primarily to employees who requested them, to actually encouraging (and in some cases, even requiring) more employees to work in newer, more flexible ways.

Suzan Lewis and colleagues found that there was an active promotion of traditional WLB policies in a number of UK public sector organizations. There was also evidence that WLB policies and flexible working practices had evolved into more strategic and employer-led practices, including combinations of remote working, hot-desking, and use of technology, alongside job analysis and redesign. The human-resource specialists reported that these practices enabled employers to reduce their estates and save money on utility costs and argued that they also helped to support WLB.

The study also found that there were changes in the ways in which HR specialists discussed WLB policies and practice. Overall, there was an evolution from focusing on employees' WLB needs and compliance with legislation (such as the right to request flexible working legislation) to more proactive, strategic approach, as described above. Accordingly, WLB was being discussed in terms of efficiency, sustaining jobs and saving money. It was also discussed in terms of mutual flexibility and benefit, but the employee perspective was not always fully considered.

\section{Evidence from southern Europe}

Dr. Rea Prouska, Senior Lecturer in HRM at Middlesex University, shared findings at the conference from two studies based in southern Europe (Prouska et al., 2015a, 2015b). The first study quantitatively examined the application of total reward practices in small and medium-sized enterprises (SMEs) in south-eastern Europe and the reward elements positively affecting organisational performance.

The sample consisted of 199 SMEs operating in south-eastern European countries which were either under economic crisis or transition: Greece, Bulgaria, Romania, Albania, Kosovo and the Former Yugoslav Republic of Macedonia (FYROM).

The study found that SMEs in the SEE region were implementing a total-rewards model which was characterised by a weaker application of individual aspects and by a stronger application of transactional, relational and communal aspects. 
Chatrakul Na Ayudhya, U., Prouska, R. and Lewis, S. (2015), "Work-life balance can benefit business during financial crisis and austerity", Human Resource Management International Digest, Vol. 23, Iss. 5 pp. 25-28.

Within the communal aspects of the model, this study found three elements of the work environment that positively affected organisational performance; WLB, employee involvement voice mechanisms, and organisational culture supporting personal and professional development.

The main conclusion of this study was that employers in these countries benefit from WLB in times of austerity and that WLB can make up for reduced financial rewards.

The second study was qualitative in nature and examined the impact of crisis and austerity on quality of working life from the perspectives of highly-skilled public and private sector professional and managerial workers in Greece.

The data were gathered at the peak of the Greek recession and consisted of 20 in-depth interviews with Greek doctors, teachers, lawyers and senior managers.

The findings presented a significant decline in quality of working life and WLB, particularly for public sector professionals. Given that these professionals sometimes deliver services to the most vulnerable of society, this study raised issues regarding the impact of the crisis on professional ethos and identity.

\section{The dual agenda approach to WLB}

Based on the evidence presented in our workshop at the conference, we considered the debate about whether WLB has become more employer-driven than employee-driven in times of financial crisis. We argued that the main lesson from the three studies is that while WLB initiatives can be good for business and a good way of managing recession and austerity, it is crucial not to lose sight of employee needs.

We then introduced and explained the dual agenda approach (Lewis and Cooper, 2005; Rapoport et al., 2002) as a potential framework for HR practitioners, managers, and employers for addressing this debate.

At the heart of the dual-agenda approach is the practice of work redesign to meet a doublegoal of increasing gender equity and organizational effectiveness. The approach argues that these two objectives are not oppositional and are in fact, interdependent. It serves to simultaneously address and enhance both the interests of employees (women and men from all phases of life, not just working mothers and working fathers) and the employer. Crucially, it recognizes that dropping either perspective (employee or employer needs) prevents positive outcomes that are mutually beneficial.

The goal of the dual agenda is not the identification of good practices as such. Rather, it is about the principles of effective processes to achieve innovations that are appropriate to specific contexts. In summary, the principles of the dual agenda approach are:

- starting by looking at a key business need (for example, the need to reduce absenteeism and turnover by empowering self-managed teams);

- working together to develop mutual understandings of working practices, underlying assumptions and their impact on the dual agenda (employees' work-life needs and workplace effectiveness);

- keeping the dual agenda in focus at all times - dropping either perspective prevents positive outcomes;

- working together to come up with of innovative solutions; 
- engaging with resistance throughout;

- experimenting with new ways of working;

- collaboratively evaluating developed pilots on new ways of working to meet the dual agenda; and

- developing mutual flexibility through collaboration rather than top down.

We believe that the role of HR in WLB is not limited to the development of policies. As strategic partners, HR specialists should be involved in assessing the needs of workers and the business and working with work teams to collaborate in finding effective working practices to meet both agendas.

Part of the main challenge for HR is to convince senior and line management of the need for flexible working arrangements. In order to do this, HR should take charge in monitoring the effectiveness of policies, including implementation and take-up rates and especially in evaluating flexible working practices that are often developed from the bottom-up. Equally important is the HR's role in developing strategies for overcoming resistance to change among managers and others, and barriers to success (for example, gendered assumptions about ideal workers who do not need time for family)

\section{Conclusion}

We conclude with some important challenges for HR professionals in this climate of financial crisis. Firstly, there is the challenge of empowering and collaborating with work teams to harness their knowledge and creativity in order to integrate the organisational and employee perspectives when designing and implementing WLB policies and practices. These will go beyond mere legal compliance to benefit all. Secondly, there is the challenge for HR to think beyond traditional financial rewards for employee performance in times of economic crisis and towards a total-rewards approach, incorporating WLB, as a viable alternative. Finally, there is the challenge for HR to develop its role in organisations as strategic partner in WLB policies and practices and to convince senior management of the importance of such an agenda in times of crisis and austerity.

\section{References}

Lewis, S., Anderson, D., Lyonette, C., Payne, N. and Wood, S. (2014), "WLB policies, practices and discourse in the context of public sector cuts", paper presented at the first ESRC Seminar on Work-Life Balance in the Recession and Beyond, Middlesex University.

Lewis, S and Cooper, C.L. (2005), Work-life integration: Case studies of organisational change, Wiley, West Sussex.

Prouska, R., Lewis, S., Dafnomili, M., and Economidou, M. (2015b). Quality of working life in times of crisis and austerity: Exploring the experiences of highly-skilled professional and managerial workers in Greece, working paper, Middlesex University.

Prouska, R., Psychogios, A.G., and Rexhepi, Y. (2015a). Rewarding employees in turbulent economies for improved organisational performance: Exploring SMEs in the south-eastern European region, working paper, Middlesex University.

Rapoport, R., Bailyn, L., Fletcher, J. and Pruitt, B. (2002), Beyond work-family balance: Advancing gender equity and workplace performance, Wiley, San Francisco. 